\title{
Perioperative, oncological and functional outcomes of the first robotic prostatectomy program in Quebec: Single fellowship-trained surgeon's experience of 250 cases
}

\author{
Naif Al-Hathal, MD; Assaad El-Hakim, MD, FRCSC \\ Hôpital du Sacré Cœur de Montréal, Montreal, Montreal, QC
}

See related article on page 333.

Cite as: Can Urol Assoc J 2013;7(9-10):316-32. hittp://dx.doi.org/10.5489/cuaj.319

Published online 0ctober 7, 2013.

\section{Abstract}

Background: Robotic-assisted radical prostatectomy (RARP) is being increasingly done in Canada. Despite this, the Canadian literature lacks publications on the oncologic and functional outcomes of RARP. The objective of this study is to report the longest single surgeon experience in the province of Quebec.

Methods: We collected prospective data from 250 consecutive patients who underwent RARP by a single fellowship trained surgeon (AEH) from October 2006 to October 2012. Mean followup was 28 months (range: 1-72). The D'Amico risk stratification distribution was $34 \%$ in low-risk, $48 \%$ in intermediate-risk and $18 \%$ in high-risk groups.

Results: The mean operation time $( \pm \mathrm{SD})$ was $194 \pm 60.6$ minutes, and estimated blood loss $318 \pm 179 \mathrm{~mL}$. The transfusion rate was only $0.4 \%$. All procedures were completed robotically. The mean hospital stay was 1.2 days, and $88 \%$ of patients were discharged on postoperative day 1 . The mean catheterization time was 7 days (range: 6-13). There were $2 \%$ major (Clavien III-IV) and $7.2 \%$ minor (Clavien I-II) postoperative complications, and no mortalities. On final pathology, $76 \%$ of patients were organ-confined and $70 \%$ specimen-confined. Pathological Gleason sum $\geq 7$ accounted for $86 \%$. Return of urinary continence (0-pads) at 3, 6, 12, and 24 months was $73.3 \%, 83.5 \%, 92.3 \%, 96.5 \%$, respectively. Potency rate (successful penetration with or without medication) at 6 , 12 , and 24 months was $49.3 \%, 85 \%$, and $95.3 \%$, respectively. Operative time and positive surgical margin (PSM) in organ-confined disease (pT2) decreased significantly after 50 cases. Seventeen patients $(6.8 \%)$ had no undetectable prostate-specific antigen (PSA) at first visit (PSA $<0.1 \mathrm{ng} / \mathrm{mL}$ ). Of remaining 233 patients, biochemical recurrence (PSA $>0.2 \mathrm{ng} / \mathrm{mL}$ ) was $4.7 \%$ (11 patients), and another $3.4 \%$ (8 patients) received early salvage radiotherapy (rising PSA, but $<0.2 \mathrm{ng} / \mathrm{mL}$ ). No patients with undetectable PSA required salvage treatments within 6 months postoperatively.

Conclusions: Our results compare favourably with high-volume RARP programs, despite mainly intermediate- to high-risk disease. Initial learning curve was estimated to be 50 cases. Fellowship training was instrumental in achieving adequate functional and oncological outcomes, while maintaining low complications rate.

\section{Introduction}

Prostate cancer is the most common non-skin cancer in Canadian men with an incidence of 121 cases/100 000 per year, and an estimated 26500 new cases diagnosed in 2012. ${ }^{1}$ Surgical management of prostate cancer includes radical retropubic prostatectomy (RRP), perineal prostatectomy (PR), laparoscopic radical prostatectomy (LRP) and robotic-assisted radical prostatectomy (RARP). About 69\% to $85 \%$ of prostatectomies are performed robotically in the United States. ${ }^{2}$ Although RARP has not been widely adopted in Canada, there is a growing pool of expertise and interest. There are presently 19 operational daVinci surgical systems (Intuitive Surgical Inc.) in Canada (personal communication via email, Daniel Minogue from Minogue Medical Inc., February 14, 2013).

Beside its known minimal invasive advantages, RARP has been shown in recent meta-analyses to improve functional outcomes when compared to open or laparoscopic prostatectomy with at least similar oncological outcomes. ${ }^{3-5}$ Urinary incontinence and erectile dysfunction remain the most feared and bothersome side effects following prostatectomy. ${ }^{6}$ Unfortunately, very few Canadian centres have reported functional and/or oncological outcomes of radical prostatectomy and most radical prostatectomies are being performed via the traditional open technique. ${ }^{7}$ The only published RARP series is by Fuller and Pautler on 305 patients. ${ }^{8}$ Therefore, the purpose of this study is to expand the Canadian robotic prostatectomy literature by reporting a single surgeon experience of RARP with complete accounts of functional and oncological outcomes, along with complications and learning curve. 


\section{Methods}

Between October 2006 and October 2012, 250 RARPs were performed by a single fellowship-trained surgeon (AEH) at Hôpital du Sacré-Coeur de Montréal (HSCM), using a 3-arm daVinci system and one assistant. Data were collected and maintained prospectively in a comprehensive database encompassing over 170 fields per patient-case. All men were followed at similar intervals $(1,3,6,9,12$ months, and then every 6 months for 5 years, and yearly thereafter) by the same surgeon. Patients were not preselected; any patient who was a surgical candidate was offered RARP.

\section{Surgical technique}

We used the athermal robotic technique of prostatectomy described during the surgeon's training, ${ }^{9}$ with few modifications. The urethral catheter was removed on postoperative day 7 without cystogram. A Jackson-Pratt (JP) drain was routinely placed and removed on postoperative day 1 .

\section{Data collection}

Patient demographics and baseline parameters were collected, including prostate-specific antigen (PSA), Gleason score, clinical stage, International Prostate Symptoms Score (IPSS) and Sexual Health Inventory for Men (SHIM). Detailed intraoperative data and postoperative complications ( $<30$ days) were recorded on a standardized data collection sheet. Postoperatively PSA values, International Prostate Symptom Score (IPSS), Sexual Health Inventory for Men (SHIM) and Erection Hardness Score (EHS) (Table 1) scores were collected at each visit.

\section{Continence}

Continence was assessed by a modified question added to the IPSS score "How many pads per 24 hours on average did you use in the past month for urinary incontinence: 0,1 security liner, 1 pad, 2 pads, 3 pads, 4 or more pads." We used a strict definition of 0 pads.

\section{Potency}

Patients who had a SHIM score of 22 to 25 and underwent bilateral nerve sparing were included in potency analysis. Potency was defined as the ability to penetrate, with a SHIM score of 17 or more (with at least a score of 3 on question number 2) and/or EHS $\geq 3$ with or without phosphodiesterase type 5 inhibitors (PDE5-I).

\section{Surgical margin}

Positive surgical margin (PSM) was defined as the presence of cancer at the inked margin.

\section{Biochemical recurrence}

Biochemical recurrence (BCR) was defined as PSA $>0.20 \mathrm{ng} /$ $\mathrm{mL}$ in patients who had an undetectable PSA $(<0.10 \mathrm{ng} / \mathrm{mL})$ at first visit. We advocated the use of early salvage radiotherapy, particularly in patients with pT3 or pT2+ (PSM) and a rising PSA, before PSA reached $0.20 \mathrm{ng} / \mathrm{mL}$.

\section{Results}

\section{Demographics}

Median patient age was $60.2 \pm 6.1$ years (range: $41-74$ ), median body mass index $27.9 \pm 4.8 \mathrm{~kg} / \mathrm{m}^{2}$ (range: $19.5-46$ ), and median follow-up $28 \pm 16.4$ months (range: 1 - 72) Median PSA at time of diagnosis was $7 \pm 5.9 \mathrm{ng} / \mathrm{mL}$ (range: 0.7-26.4) and transrectal ultrasound (TRUS) prostate volume $35.8 \pm 15.5 \mathrm{~mL}$ (range: 12-101). Preoperative Gleason sum 7 or more accounted for $59.2 \%$ and clinical stage T2-T3 for $37.6 \%$ (Table 2). D'Amico risk stratification distribution was $34 \%$ in low-risk, $48 \%$ intermediate-risk and $18 \%$ high-risk groups.

\section{Operative data}

Median operative (OR) time was $194 \pm 60.6$ minutes with a zero conversion rate. Estimated blood loss (EBL) was $318 \pm 179 \mathrm{~mL}$ and only 1 patient $(0.4 \%)$ required blood transfusion. Average catheterization time was 7 days (range: 6-13). Mean hospital stay was 1.2 days and $88 \%$ of patients were discharged on postoperative day 1 (Table 3 ).

\section{Complications}

There were a total of $5(2 \%)$ major postoperative complications. Of these 5 patients, $2(0.8 \%)$ had pulmonary embolism (Clavien IVa) within 1 month of surgery and successfully treated with anticoagulation. Two other patients $(0.8 \%)$ had myocardial infarction (Clavien IVa), one treated medically and the other underwent coronary artery bypass surgery. The fifth patient had incisional hernia (Clavien IIIb).

All 5 patients had fully functional recovery. Intraoperatively, within the first 25 cases, there was 1 rectal injury (Clavien IIIb), which was identified and closed primarily with no further consequences (JP drain and antibiotics for 1 week). There was no perioperative mortality. There was 1 urinary leak that resolved spontaneously with prolonged 
Al-Hathal et al.

\begin{tabular}{cl}
\hline Table & 1. Erection Hardness Score \\
\hline Score & \multicolumn{1}{c}{ Description } \\
\hline 1 & Penis does not enlarge \\
2 & Penis is larger but not hard enough for penetration \\
3 & $\begin{array}{l}\text { Penis is hard enough for penetration but not completely } \\
\text { hard }\end{array}$ \\
4 & Penis is completely hard and fully rigid. \\
\hline
\end{tabular}

drainage and catheterization (Table 4). ${ }^{10}$ There was 1 case of anastomotic stricture that required endoscopic incision, and another case of anastomotic clip migration with stone formation that required endoscopic removal, both beyond the perioperative period ( $>90$ days).

\section{Pathological data}

The mean specimen weight was $47.1 \pm 15.4 \mathrm{~g}$ (range: 22-133). On final pathology, 34\% were non-organ confined $(\geq \mathrm{pT} 3)$. Pathological Gleason sum 7 or more accounted for $86 \%$, including $10 \%$ Gleason 8 to 10 . Overall PSM rate was $30 \%$. The PSM was $25.7 \%$ in pT2 and $43.3 \%$ in pT3 disease (Table 5).

\section{Functional outcomes}

The rate of urinary continence recovery (0-pads) was $42.3 \%$ at 1 month, $73.3 \%$ at 3 months, $83.5 \%$ at 6 months, $92.3 \%$ at 12 months and $96.5 \%$ at 24 months (Table 6).

There were 77 patients with preoperative SHIM scores between 22 and 25 who were included in potency analysis. Potency rate (successful penetration with or without medication) was $49.3 \%$ at 6 months, $85 \%$ at 12 months and $95.3 \%$ at 24 months. Of note, 214 patients $(85.6 \%)$ had bilateral nerve sparing and 27 patients $(10.8 \%)$ had unilateral nerve sparing. Only 9 patients (3.6\%) had bilateral wide excision of neurovascular bundle. The questionnaire return rates by patients were $91.6 \%, 78 \%, 82.8 \%, 83.6 \%, 82.4 \%, 81.5 \%$ at $1,3,6,12,18$ and 24 months, respectively.

\section{Biochemical recurrence}

There were 17 patients whose PSA did not reach undetectable levels at first visit (PSA $<0.1 \mathrm{ng} / \mathrm{mL}$ ) and were treated with androgen deprivation therapy (ADT) \pm radiotherapy. Of the remaining 233 patients, $11(4.7 \%)$ had BCR (PSA $>0.2 \mathrm{ng} / \mathrm{mL}$ ) at mean follow-up of 26.1 months and required either radiotherapy alone or in combination with ADT. In addition, there were 8 cases $(3.4 \%)$ that were electively referred for early salvage radiotherapy for rising PSA that did not reach $0.2 \mathrm{ng} / \mathrm{mL}$. BCR-free rate at 12 months was $95.8 \%$. There were no patients with undetectable PSA who required salvage treatments within 6 months postoperatively.

\begin{tabular}{|c|c|c|}
\hline Variable & Mean \pm SD & Range/rate \\
\hline Age (years) & $60.2 \pm 6.1$ & $41-74$ \\
\hline BMI $\left(\mathrm{kg} / \mathrm{m}^{2}\right)$ & $27.9 \pm 4.8$ & $19.5-46$ \\
\hline Preoperative PSA (ng/mL) & $7 \pm 5.9$ & $0.7-26.4$ \\
\hline Prostate volume (mL) & $35.8 \pm 15.5$ & $12-101$ \\
\hline \multicolumn{3}{|l|}{ Gleason sum (n, \%) } \\
\hline G6 & 102 & $40.8 \%$ \\
\hline G7 & 127 & $50.8 \%$ \\
\hline G8 & 16 & $6.4 \%$ \\
\hline G9 & 5 & $2 \%$ \\
\hline \multicolumn{3}{|l|}{ Clinical stage (n, \%) } \\
\hline $\mathrm{T} 1 \mathrm{a} / 1 \mathrm{~b}$ & 1 & $0.4 \%$ \\
\hline T1c & 155 & $62 \%$ \\
\hline $\mathrm{T} 2 \mathrm{a}$ & 86 & $34.4 \%$ \\
\hline $\mathrm{T} 2 \mathrm{~b}$ & 6 & $2.4 \%$ \\
\hline T3 & 2 & $0.8 \%$ \\
\hline
\end{tabular}

SD: standard deviation; BMl: body mass index; PSA: prostate-specific antigen.

\section{Learning curve}

OR time deceased significantly after the first 50 cases by an average of 80 minutes. Mean OR time for consecutive quintile (50 patients) was $260 \pm 65$ minutes, $190 \pm 50$ minutes, $170 \pm 45$ minutes, $170 \pm 32$ minutes, and $180 \pm 64$ minutes (Table 7). We performed only 1 case per day until 58th case, and then we routinely operated on 2 patients per day. In addition, after the 35th case we got a stable bedside surgical nurse assistant.

PSM in organ-confined disease (pT2) per consecutive quintiles were $36.1 \%, 17.1 \%, 27.9 \%, 23.6 \%$, and $23.6 \%$, respectively. There was a significant improvement after 50 cases (Table 7).

\section{Discussion}

We report the longest single surgeon experience of RARP in the province of Quebec, with complete accounts of perioperative, functional and oncological outcomes. There is a paucity of Canadian prostatectomy experience in the medical literature, of any surgical approach. We compare our

\begin{tabular}{lc}
\hline Table 3. Operative data & \\
\hline Mean operation time (robot time) \pm SD $(\mathrm{min})$ & $194 \pm 60.6$ \\
Mean operation time (skin to skin) \pm SD $(\mathrm{min})$ & $224 \pm 60$ \\
Conversion rate $(\%)$ & 0 \\
Mean blood loss $\pm \mathrm{SD}(\mathrm{mL})$ & $318 \pm 179$ \\
Transfusion rate, $\mathrm{n}(\%)$ & $1(0.4 \%)$ \\
Mean catheterization time, range (days) & $7.1(6-13)$ \\
Mean hospital stay $\pm \mathrm{SD}$ (days) & $1.23 \pm 0.73$ \\
\hline SD: standard deviation.
\end{tabular}




\begin{tabular}{lcc}
\hline \multicolumn{3}{l}{ Table 4. Perioperative complications (<30 days) } \\
\hline \multicolumn{2}{l}{$\mathbf{n}(\%)$} & Clavien classification ${ }^{10}$ \\
\hline Intraoperative & & $\mathrm{Illb}$ \\
Inferior epigastric injury & $3(1.2)$ & $\mathrm{Illb}$ \\
Bladder and/or urethral tear & $3(1.2)$ & $\mathrm{Illb}$ \\
Rectal Injury & $1(0.4 \%)$ & \\
Postoperative & & $\mathrm{IVa}$ \\
Pulmonary embolism & $2(0.8 \%)$ & $\mathrm{IVa}$ \\
Myocardial infarction & $2(0.8 \%)$ & $\mathrm{Illb}$ \\
Incisional hernia & $1(0.4 \%)$ & $\mathrm{II}$ \\
Wound infection & $2(0.8 \%)$ & $\mathrm{II}$ \\
Urinary tract infection & $2(0.8 \%)$ & $\mathrm{II}$ \\
Arrhythmia & $1(0.4 \%)$ & $\mathrm{II}$ \\
Epididymo orhchitis & $1(0.4)$ & $\mathrm{II}$ \\
Pelvic hematoma & $1(0.4 \%)$ & $\mathrm{I}$ \\
Hematuria & $3(1.2 \%)$ & $\mathrm{I}$ \\
Acute renal failure & $2(0.8 \%)$ & $\mathrm{I}$ \\
Ileus & $2(0.8 \%)$ & $\mathrm{I}$ \\
Neuromuscular & $2(0.8)$ & $\mathrm{I}$ \\
Urinary leak & $1(0.4 \%)$ & $\mathrm{I}$ \\
Reynaud's phenomenon & $1(0.4 \%)$ & \\
\hline
\end{tabular}

results with available functional and oncological outcomes reported from Canadian centres.

Urinary incontinence is the most bothersome side effect following prostatectomy and is a major source of patient anxiety early on the postoperative period. ${ }^{6,11}$ We used a strict definition of 0-pads to report the rate of urinary continence. The early continence rate at 3 months was $73.3 \%$, which improved to $92.3 \%$ at 12 months and $96.5 \%$ at 24 months. Fuller and Pautler reported a 70\% no-pad use at 1 year. ${ }^{8}$ The University of Alberta group reported continence rates post-RRP of $57 \%$ at 3 months, and $85 \%$ at 12 months (definition of incontinence, $<8 \mathrm{~g}$ of urine loss on the pad test per day). ${ }^{12}$ In another prospective study from the same group, 239 patients were studied (172 RRP and 67 LRP). According to the 24 -hour pad test, $13 \%$ of RRP patients and $17 \%$ of LRP patients remained incontinent at 1 year. ${ }^{13}$ In a recent systematic review and meta-analysis on urine incontinence after RARP from high-volume centres worldwide, the weighted mean rate of urine continence at 12 months was $84 \%$ (range: 69-96) using the no-pad definition. ${ }^{4}$

In the era of PSA screening, younger patients with good functional status are being diagnosed with prostate cancer. ${ }^{14}$ Therefore, all efforts are made to preserve quality of life in the postoperative period. In the current cohort, $85.6 \%$ of patients had bilateral and $10.8 \%$ unilateral nerve sparing. The potency rate was $49.3 \%$ at 6 months, $82 \%$ at 12 months and $95.3 \%$ at 24 months. Coelho and colleagues performed a meta-analysis on potency after RARP from pooled literature of centres of excellence. ${ }^{15}$ Weighted mean potency rates were $61.1 \%, 71.2 \%$ and $94 \%$ at 6,12 and $>18$ months, respectively. In a population-based study from a Quebec-

\begin{tabular}{|c|c|c|}
\hline \multicolumn{3}{|l|}{ Pathological stage (n, \%) } \\
\hline pT2a & 55 & $22 \%$ \\
\hline pT2b & 135 & $54 \%$ \\
\hline pT3a & 44 & $17.6 \%$ \\
\hline pT3b & 13 & $5.2 \%$ \\
\hline pT3c & 3 & $1.2 \%$ \\
\hline \multicolumn{3}{|l|}{ Pathological Gleason sum (n, \%) } \\
\hline G5 & 1 & $0.4 \%$ \\
\hline G6 & 34 & $13.6 \%$ \\
\hline G7 & 190 & $76 \%$ \\
\hline G8 & 15 & $6 \%$ \\
\hline G9 & 9 & $3.6 \%$ \\
\hline G10 & 1 & $0.4 \%$ \\
\hline Prostate weight $\pm \mathrm{SD}$, range $(\mathrm{g})$ & $47.1 \pm 15.4$ & $22-133$ \\
\hline Overall PSM (fraction, \%) & $75 / 250$ & $30 \%$ \\
\hline PSM pT2 (fraction, \%) & $49 / 190$ & $25.7 \%$ \\
\hline $\mathrm{pT} 2 \mathrm{a}$ & $11 / 55$ & $20 \%$ \\
\hline pT2b & $38 / 135$ & $28.1 \%$ \\
\hline PSM pT3 (fraction, \%) & $26 / 60$ & $43.3 \%$ \\
\hline рT3a & $13 / 44$ & $29.5 \%$ \\
\hline pT3b & $12 / 13$ & $92.3 \%$ \\
\hline pT3c & $1 / 3$ & $33.3 \%$ \\
\hline
\end{tabular}

wide RRP cohort between 1988 and 1996, Karakiewicz and colleagues studied 2227 men without erectile dysfunction before surgery. Of these men, only $25 \%$ reported erections of adequate firmness for intercourse. ${ }^{16}$ To our knowledge no other Canadian series reported erectile function outcomes after prostatectomy.

In this cohort we report low complication rates. There were a total of 23 postoperative complications: $2 \%$ major, $7.2 \%$ minor and $0.8 \%$ required further intervention. Fuller and Pautler recorded 70 complications in 350 RARP cases: $7.5 \%$ major, $15.4 \%$ minor and overall $5.2 \%$ required further intervention. ${ }^{8}$ Our mean hospital stay of 1.2 days matches large RARP series in the United States, but was significantly lower than in a reported Canadian series of LRP $(3.4 \text { days })^{17}$ and RARP ( 3 days). ${ }^{8}$

Overall the PSM rate was $30 \%$, subdivided into $25.7 \%$ for $\mathrm{pT} 2$ and $43.3 \%$ for $\mathrm{pT} 3$ disease. Fradet and colleagues

\begin{tabular}{|c|c|c|}
\hline Time (months) & 0 -pads $(\%)$ & 1-security liner (\%) \\
\hline 1 & $42.3 \%$ & $51.5 \%$ \\
\hline 3 & $73.3 \%$ & $80.0 \%$ \\
\hline 6 & $83.5 \%$ & $87.4 \%$ \\
\hline 12 & $92.3 \%$ & $93.7 \%$ \\
\hline 18 & $95.1 \%$ & $96.1 \%$ \\
\hline 24 & $96.5 \%$ & $97.0 \%$ \\
\hline
\end{tabular}


Al-Hathal et al.

\begin{tabular}{|c|c|c|c|}
\hline Quintiles & $\begin{array}{l}\text { Mean operation } \\
\text { time } \pm \text { SD (min) }\end{array}$ & $\begin{array}{c}\text { Overall PSM, } \\
\text { fraction (\%) }\end{array}$ & $\begin{array}{l}\text { PSM in pT2, } \\
\text { fraction (\%) }\end{array}$ \\
\hline First 50 cases & $260 \pm 65$ & 19/50 (38\%) & $13 / 36(36.1 \%)$ \\
\hline Second 50 cases & $190 \pm 50$ & $13 / 50$ (26\%) & 6/35 (17.1\%) \\
\hline Third 50 cases & $170 \pm 45$ & $14 / 50$ (28\%) & $12 / 43(27.9 \%)$ \\
\hline Forth 50 cases & $170 \pm 32$ & $13 / 50(26 \%)$ & 9/38 (23.6\%) \\
\hline Fifth 50 cases & $180 \pm 64$ & $16 / 50(32 \%)$ & $9 / 38(23.6 \%)$ \\
\hline
\end{tabular}

SD: standard deviation; PSM: positive surgical margin.

from Quebec City reported an overall PSM rate of 34.5\% in 1712 RRP. ${ }^{18}$ Corcoran and colleagues reported a $24.4 \%$ PSM rate in 1514 patients who underwent RRP from a combined series of University of British Columbia and University of Melbourne. ${ }^{19}$ In our series, PSM rate is in part due to a higher rate during the initial experience and because most patients fall in the intermediate- (48\%) and high-risk (18\%) groups. Furthermore, we adopted an aggressive nerve-sparing approach, which may have contributed to PSM. After the first 50 cases, the PSM rate in pT2 was $23.4 \%$, which is comparable to published literature after initial experience, ${ }^{20-22}$ and lower than in population-based studies. ${ }^{23}$ Fuller and Pautler reported an overall PSM rate of $16.1 \%$ in their cohort of low- to intermediate-risk RARP, with $10.2 \%$ for pT 2 and $32 \%$ for pT $3 .{ }^{8}$ In Ontario, the median provincewide PSM rate for pT2 disease was 33\% among 43 hospitals, with RRP volumes ranging 12 to 625 , with no differences between community and teaching hospitals. ${ }^{23}$ The University of Toronto group reported an overall 20.8\% PSM in 1268 men who underwent RRP between 1992 and 2008. ${ }^{24}$

In this cohort we met all goals established by Cancer Care Ontario guidelines on radical prostatectomy, namely positive margin rate of $<25 \%$ for $\mathrm{pT} 2$ disease, a mortality rate of $<1 \%$, rates of rectal injury of $<1 \%$ and blood transfusion rates of $<10 \% .{ }^{25}$

As with any new robotic program, we encountered several challenges at the beginning of our experience. Patel and colleagues reported few major challenges during their initial experience which were related to lack of haptic feedback, inexperience with the robot-assisted laparoscopic approach, and the remoteness of the surgeon from the patient. ${ }^{26}$ In our experience, these difficulties were not encountered as the primary surgeon (AEH) had formal fellowship training in robotic prostatectomy. The main challenges included the inexperience of the ward staff in the RARP care, the anesthetic team's unfamiliarity with the procedure, the scarce case scheduling, the changing bedside assistant until the 35th case, the longer setup and turnover times, and the alterations in surgical technique to optimize outcomes with only 1 assistant on a 3-arm robot. Efficiency was reached after 50 cases and the mean OR time deceased by an average of 80 minutes. In addition, the PSM rate in organ-confined disease (pT2) improved significantly after 50 cases. This improvement in PSM rate and OR concurs with the experience of other groups. ${ }^{27,28}$ The learning curve for prostate cancer recurrence after radical prostatectomy is even longer and was estimated at 250 cases. ${ }^{29}$ These daunting figures are best appreciated in a broader context. For example, of the 2861 RRPs performed in Quebec between 1988 and 1993, on average $80 \%$ were by urologists using this surgery 12 times or less annually. ${ }^{30}$

Our results compare favourably with RARP centres of excellence (Table 8), ${ }^{20,27,31-41}$ despite initial difficulties and operating mainly on patients with intermediate- to high-risk disease.

\begin{tabular}{|c|c|c|c|c|c|c|c|}
\hline Series & Technique & $\mathbf{n}$ & $\begin{array}{l}\text { Mean FU } \\
\text { (months) }\end{array}$ & PSM (\%) & $\begin{array}{c}\text { Intercourse at } 1 \\
\text { year (\%) }\end{array}$ & $\begin{array}{c}\text { Pad-free at } 1 \text { year } \\
(\%)\end{array}$ & $\mathrm{BCR}$ at 1 year $(\%)$ \\
\hline Rabbani et al. ${ }^{32}$ & Open & 225 & 12 & NA & 42 & NA & NA \\
\hline Schover et al..$^{33}$ & Open & 240 & 52 & NA & NA & NA & NA \\
\hline Guillonneau et al..$^{34}$ & Lap & 550 & 36 & 16.7 & 66 & 82 & 14 \\
\hline Hoznek et al. ${ }^{35}$ & Lap & 134 & 12 & 25 & 5.6 & 86 & 11 \\
\hline Rassweiler et al. ${ }^{36}$ & Lap & 438 & 12 & 30 & NA & 90 & 13.2 \\
\hline Stolzenburg et al. ${ }^{37}$ & Lap & 70 & 12 & 21 & $33(6 \mathrm{mo})$ & 90 (6 months) & NA \\
\hline Hara et al. ${ }^{38}$ & Lap/open & 52 & 6 & NA & NA & NA & NA \\
\hline Ahlering et al. ${ }^{20}$ & RARP & 60 & 9 & 17 & $33(9 \mathrm{mo})$ & 76 (3 months) & NA \\
\hline Patel et al. ${ }^{27}$ & RARP & 200 & 9.7 & 21 & NA & 98 & 5 \\
\hline Bentas et al. ${ }^{39}$ & RARP & 40 & 15 & 30 & 22 & 84 (15 months) & NA \\
\hline Menon et al. ${ }^{40}$ & RARP & 200 & 7.9 & 6 & 68 & 90 & 4 \\
\hline Tewari et al. ${ }^{41}$ & RARP & 530 & 12 & 9 & 78 & 98 & 4 \\
\hline Kaul et al. ${ }^{31}$ & RARP & 154 & 12 & 6.4 & 96 & 97 & 0 \\
\hline Present study & RARP & 250 & 28 & 30 & 85 & 92.3 & 4.2 \\
\hline
\end{tabular}




\section{Conclusion}

Our results compare favourably with high-volume RARP programs, despite mainly intermediate- to high-risk disease. Initial learning curve was estimated to be 50 cases. Fellowship training was instrumental in achieving adequate functional and oncological outcomes, while maintaining low complications rate.

Acknowledgment: Ministry of higher education in Saudi Arabia for providing scholarship to Dr. Naif Al-Hathal in support of his fellowship training.

Competing interests: None declared.

This paper has been peer-reviewed.

\section{References}

1. Canadian Cancer Society/National Cancer Institute of Canada. Canadian Cancer Statistics 2012. Toronto: Canadian Cancer Society \& National Cancer Institute of Canada; 2012.

2. Lowrance WT, Parekh DJ. The rapid uptake of robotic prostatectomy and its collateral effects. Cancer 2012;1 18:4-7. http://dx.doi.org/10.1002/cncr.26275

3. Berryhill R Jr, Jhaveri J, Yadav R, et al. Robotic prostatectomy: a review of outcomes compared with laparoscopic and open approaches. Urology 2008;72:15-23. http://dx.doi.org/10.1016/i.urology.2007.12.038

4. Ficarra V, Novara G, Rosen RC, et al. Systematic review and meta-analysis of studies reporting urinary continence recovery after robot-assisted radical prostatectomy. Eur Urol 2012;62:405-17. http://dx.doi. org/10.1016/i.eururo.2012.05.045

5. Rocco B, Matei DV, Melegari S, et al. Robotic vs open prostatectomy in a laparoscopically naive centre: a matched-pair analysis. BJU Int 2009;104:991-5. http://dx.doi.org/10.1111/i.1464410X.2009.08532.x

6. Miller DC, Sanda MG, Dunn RL, et al. Long-term outcomes among localized prostate cancer survivors: health-related quality-of-life changes after radical prostatectomy, external radiation, and brachytherapy. J Clin Oncol 2005;23:2772-80. http://dx.doi.org/10.1200/JC0.2005.07.116

7. Grover SA, Coupal L, Zowall H, et al. The economic burden of prostate cancer in Canada: forecasts from the Montreal Prostate Cancer Model. CMAJ 2000;162:987-92.

8. Fuller A, Pautler SE: Complications following robot-assisted radical prostatectomy in a prospective Canadian cohort of 305 consecutive cases. Can Urol Assoc J 2012; Epub 2012 Mar 2. http://dx.doi.org/10.5489/ cuaj.11116

9. El-Hakim A, Leung RA, Richstone L, et al. Athermal Robotic Technique of prostatectomy in patients with large prostate glands (>75 g): technique and initial results. BJU Int 2006;98:47-9. http://dx.doi. org/10.1111/.i.1464-410X.2006.06252.x

10. Clavien PA, Sanabria JR, Strasberg SM. Proposed classification of complications of surgery with examples of utility in cholecystectomy. Surgery 1992;111:518-26.

11. Penson DF, Mclerran D, Feng $Z$, et al. 5-year urinary and sexual outcomes after radical prostatectomy: results from the prostate cancer outcomes study. J Urol 2005;173:1701-5. http://dx.doi. org/10.1097/01.ju.0000154637.38262.3a

12. Moore KN, Truong V, Estey E, et al. Urinary incontinence after radical prostatectomy: can men at risk be identified preoperatively? J Wound Ostomy Continence Nurs 2007;34:270-9; quiz 280-1.

13. Jacobsen NE, Moore KN, Estey E, et al. Open versus laparoscopic radical prostatectomy: a prospective comparison of postoperative urinary incontinence rates. J Urol 2007;177: 615-9. http://dx.doi. org/10.1016/i.juro.2006.09.022

14. Pelzer AE, Tewari A, Bektic J, et al. Detection rates and biologic significance of prostate cancer with PSA less than $4.0 \mathrm{ng} / \mathrm{mL}$ : observation and clinical implications from Tyrol screening project. Urology 2005;66:1029-33. http://dx.doi.org/10.1016/i.urology.2005.05.025
15. Coelho RF, Chauhan S, Palmer KJ, et al. Robotic-assisted radical prostatectomy: a review of current outcomes. BJU Int 2009;104:1428-35. http://dx.doi.org/10.1111/j.1464-410X.2009.08895.x

16. Karakiewicz PI, Tanguay $S$, Kattan MW, et al. Erectile and urinary dysfunction after radical prostatectomy for prostate cancer in Quebec: a population-based study of 2415 men. Eur Urol 2004; 46:188-94. http:// dx.doi.org/10.1016/i.eururo.2004.04.020

17. Al-Shaiji TF, Kanaroglou N, Thom A, et al. A cost-analysis comparison of laparoscopic radical prostatectomy versus open radical prostatectomy: the McMaster Institute of Urology experience. Can Urol Assoc J 2010;4:237-41. http://dx.doi.org/10.5489/cuaj.09166

18. Mavermann J, Fradet V, Lacombe L, et al. The Impact of Solitary and Multiple Positive Surgical Margins on Hard Clinical End Points in 1712 Adjuvant Treatment-Naive pT2-4 NO Radical Prostatectomy Patients. Eur Urol 2013;64:19-25. http://dx.doi.org/10.1016/i.eururo.2012.08.002. Epub 2012 Aug 10.

19. Corcoran NM, Hovens CM, Metcalfe C, et al. Positive surgical margins are a risk factor for significant biochemical recurrence only in intermediate-risk disease. BJU Int 2012;110:821-7. http://dx.doi. org/10.1111/j.1464-410X.2011.10868.x

20. Ahlering TE, Woo D, Eichel L, et al. Robot-assisted versus open radical prostatectomy: a comparison of one surgeon's outcomes. Urology 2004;63:819-22. http://dx.doi.org/10.1016/i.urology.2004.01.038

21. Ficarra $V$, Cavalleri $S$, Novara $G$, et al. Evidence from robot-assisted laparoscopic radical prostatectomy: a systematic review. Eur Urol 2007;51:45-55; discussion 56. http://dx.doi.org/10.1016/i. eururo.2006.06.017

22. Liss $M$, Osann $K$, Ornstein D. Positive surgical margins during robotic radical prostatectomy: a contemporary analysis of risk factors. BJU Int 2008;102:603-8. http://dx.doi.org/10.1111/j.1464410X.2008.07672.x

23. Lawrentschuk N, Evans A, Srigley J, et al. Surgical margin status among men with organ-confined (pT2) prostate cancer: a population-based study. Can Urol Assoc J 201 1;5:161-6. http://dx.doi.org/10.5489/cuaj.10085

24. Alkhateeb $S$, Alibhai $S$, Fleshner N, et al. Impact of positive surgical margins after radical prostatectomy differs by disease risk group. J Urol 2010;183:145-50. http://dx.doi.org/10.1016/i.juro.2009.08.132

25. Chin JL, Srigley J, Mayhew LA, et al. Guideline for optimization of surgical and pathological quality performance for radical prostatectomy in prostate cancer management: evidentiary base. Can Urol Assoc J 2010;4:13-25. http://dx.doi.org/10.5489/cuaj.08105

26. Patel VR, Thaly R, Shah K. Robotic radical prostatectomy: outcomes of 500 cases. BJU Int 2007;99:110912. http://dx.doi.org/10.1111/j.1464-410X.2007.06762.x

27. Patel VR, Tully AS, Holmes R, et al. Robotic radical prostatectomy in the community setting-the learning curve and beyond: initial 200 cases. J Urol 2005;174:269-72. http://dx.doi.org/10.1097/01. ju.0000162082.12962.40

28. Ahlering TE, Eichel L, Edwards RA, et al. Robotic radical prostatectomy: a technique to reduce $\mathrm{pT} 2$ positive margins. Urology 2004;64:1224-8. http://dx.doi.org/10.1016/i.urology.2004.08.021

29. Vickers AJ, Bianco FJ, Serio AM, et al. The surgical learning curve for prostate cancer control after radical prostatectomy. J Natl Cancer Inst 2007;99:1171-7. http://dx.doi.org/10.1093/inci/dim060

30. Karakiewicz Pl, Zini A, Meshref AW, et al. Population-based patterns of radical retropubic prostatectomy use. Urology 1998;52:219-23. http://dx.doi.org/10.1016/S0090-4295(98)00176-9

31. Kaul S, Savera A, Badani K, et al. Functional outcomes and oncological efficacy of Vattikuti Institute prostatectomy with Veil of Aphrodite nerve-sparing: an analysis of 154 consecutive patients. BJU Int 2006;97:467-72. http://dx.doi.org/10.1111/i.1464-410X.2006.05990.x

32. Rabbani F, Scardino PM. Time course of recovery of potency after bilateral nerve sparing radical prostatectomy. J Urol 2004;171 (Suppl):abstract 310.

33. Schover LR, Fouladi RT, Warneke CL, et al. Defining sexual outcomes after treatment for localized prostate carcinoma. Cancer 2002;95:1773-85. http://dx.doi.org/10.1002/cncr.10848

34. Guillonneau B, Cathelineau X, Doublet ID, et al. Laparoscopic radical prostatectomy: assessment after 550 procedures. Crit Rev Oncol Hematol 2002;43:123-33. http://dx.doi.org/10.1016/S10408428(02)00024-0

35. Hoznek A, Salomon L, Olsson LE, et al. Laparoscopic radical prostatectomy. The Creteil experience. Eur Urol 2001;40:38-45. http://dx.doi.org/10.1159/000049747

36. Rassweiler J, Schulze M, Teber D, et al. Laparoscopic radical prostatectomy: functional and oncological outcomes. Curr Opin Urol 2004;14:75-82. http://dx.doi.org/10.1097/00042307-200403000-00005

37. Stolzenburg JU, Do M, Rabenalt $R$, et al. Endoscopic extraperitoneal radical prostatectomy: initial experience after 70 procedures. J Urol 2003;169:2066-71. http://dx.doi.org/10.1097/01. ju.0000067220.84015.8e

38. Hara I, Kawabata G, Miyake H, et al. Comparison of quality of life following laparoscopic and open prostatectomy for prostate cancer. J Urol 2003;169:2045-8. http://dx.doi.org/10.1097/01. ju.0000063961.99940.6c

39. Bentas W, Wolfram M, Jones J, et al. Robotic technology and the translation of open radical prostatectomy to laparoscopy: the early Frankfurt experience with robotic radical prostatectomy and one year follow-up. Eur Urol 2003;44:175-81. http://dx.doi.org/10.1016/S0302-2838(03)00256-2 
Al-Hathal et al.

40. Menon M, Tewari A, Baize B, et al. Prospective comparison of radical retropubic prostatectomy and robotassisted anatomic prostatectomy: the Vattikuti Urology Institute experience. Urology 2002;60:864-8. http://dx.doi.org/10.1016/S0090-4295(02)01881-2

41. Tewari A, Kaul S, Menon M. Robotic radical prostatectomy: a minimally invasive therapy for prostate cancer. Curr Urol Rep 2005;6:45-8. http://dx.doi.org/10.1007/s1 1934-005-0066-6
Correspondence: Dr. Assaad El-Hakim, Chief, Robotic Urology, Hôpital du Sacré Cœur de Montréal, 5400, boul. Gouin Ouest, Montréal (Québec) H4J 1C5; assaad.elhakim@gmail.com 